\title{
DISCOVERING REALITY THROUGH THE CAMERA
}

\author{
P.P. STRONA \\ Independent Researcher, Torino, Italy.
}

\begin{abstract}
This article presents reflections on the role photography plays in the perception of reality, showing how the image that catches a certain place at a certain moment in time enables the observer to perceive details that might have escaped his notice had he been there himself at that place and time. It goes on to speak in great detail about creative photography, focusing especially on the role of light and ways of capturing images that are meaningful and representative of reality, which can reveal even its hidden structures. Particular attention is paid to light by day and by night, to landscapes and townscapes, to water and glass, all important factors in our perception of the world around us. Lastly, the importance of the framing, lenses and point of view from which a shot is taken is considered and some attention is paid to how varying points of view can catch and communicate not only the various aspects of what is represented but also the emotions that can be felt as one experiences certain situations and special moments in time.

Keywords: Capturing light, communication of emotions, framing a photograph, hidden geometries, images in glass and water, landscapes, lenses, perception of the reality, photography, townscapes.
\end{abstract}

\section{INTRODUCTION}

As we look around us, we realize that everything our minds perceive through our eyes changes continually: nothing is static. Light makes everything around us visible to our eyes but it continually changes the forms, the shades of the colours, the importance of the various details according to the seasons, the day, the time and the weather at that precise moment. Every instant is unique and can never be repeated.

Besides, every person, too, changes continually. Each of us is born with specific characteristics, has different experiences and forms relationships with other people, cultivates personal interests and, in the course of time, builds up his or her own culture and develops more or less pronounced sensitivity to the various kinds of reality in which he or she lives. Consequently, the beauty of what surrounds us and the events we are involved in stimulate each of us in a different, subjective way; each of us filters reality through his or her own personality, arousing more or less intense emotions within himself or herself.

Yet, if we turn our attention to the past, we realize that since prehistoric times, man has always sought to go beyond these limits, and to represent reality as objectively as possible, to understand it better and to communicate it to other people. He did so in the caves, in the simple but powerful drawings he carved in the rock, and he has continued to do so down the ages, in paintings, frescoes and sculptures, improving the techniques of graphic art, of drawing and developing the principles of perspective.

Later, research went beyond the aspects most closely limited to the scene presented, its setting and depth. Attention was directed to the element of 'light', which creates all visual perception.

The works of the Flemish painter Rubens, the Italian Caravaggio and the English painter Turner, all reveal exceptional sensitivity to the effects of light. But at the end of the 19th century, in the work of the Impressionist painters, light became perhaps the most important feature in pictorial representation. Monet's water lilies are an outstanding example of this.

Then, at the beginning of the 20th century, abstract painters began to search for and to highlight the structures hidden in real objects. The representation of the tree in the work of Mondrian throws light on this process. If we follow this tree from painting to painting, we see that it is gradually 
transformed, revealing its inner structure, until at last it loses all objective reference to our idea of a tree and becomes a harmonious composition in its proportions and colours, just pure geometrical beauty.

The art of photography, which first began in the 19th century, has evolved and is still evolving, over a much shorter period of time, along lines analogous to those of painting.

A photograph can now be snapped in an instant, it does not require complex techniques or long hours of work as painting a picture does. From this point of view, anyone can take a photograph as long as they have access to a camera. It is the motivation and the purpose that are the same as for painting.

At first the photographer simply tried to get a scene on paper, to document an event so as to communicate it to those who were not present at the time. But later attention was extended to other aspects, such as:

- To capture the element essential to create the image, the 'light'.

- The search for beauty, by studying the best frame and angle for the shot, the proportions and forms and by bringing out the various planes.

- The search for hidden structures, the geometry.

- The creation of images capable of communicating effectively the emotions experienced at a given time and place, as we contemplate, for example, a landscape or a townscape, or carry out some activity, mountain climbing, sailing, factory or laboratory work, etc.

Hence, today, photography is no longer just a means of remembering, it has become a new expressive language capable of communicating knowledge and emotions, a true figurative art, even capable of entering the sphere of abstract art. So like all forms of art, it is an instrument with which man can improve his knowledge of the world in which he lives and his knowledge of himself.

\section{PHOTOGRAPHIC REPRESENTATION}

Today a photographer can use a camera to fix on paper everything he or she sees around him or her at a given place and time, trying to catch its essential beauty and to represent and communicate his or her personal perception of it to others.

However, as we have already said, every instant is unique and unrepeatable and the photographer too is unique. He or she filters reality subjectively and, in deciding whether or not to take a picture, he or she is motivated both by his or her personal characteristics and by aspects of the scene before him or her that have struck him or her particularly, as well as the wish to render and communicate what he or she is feeling at that moment. In his or her place, other people would presumably have caught different aspects of the same scene and so created different images.

However, no sooner has the photograph been fixed on paper that instant has been transferred and can be observed and analysed later, over and over again, at length and with care. Hence, the observer will be able to notice details which the photographer may not have seen when he or she took the picture and discover others which he or she would not have noticed had he or she been there at the time.

So photography enables us to discover aspects of reality which exist, which are there before our eyes, but which we often fail to see. It broadens our capacity to feel, developing our powers to observe and see the reality around us more fully.

As the photographer takes a photograph, he or she wishes to communicate what has struck him or her, but actually he or she does much more than this, since the photographer enables us to discover aspects of reality which he or she had not noticed, which can now be seen by anyone in the image 
created. So, in a way, anyone who looks at a photograph can become an artist, as he or she interprets it. And in the same way, the photographer, too, may later discover new aspects of reality in those same pictures.

To get a better understanding of this argument, analogies can be drawn with other forms of art, for example, music.

The composers write a piece of music, following their creative impulse and developing an idea that they have. However, once written down on paper, the music can be interpreted in infinite ways by the various musicians who play it, at different times in history. The composers may never have thought of such interpretations and might never have been able to imagine them and yet they were present, hidden in the score they had written, the music existed potentially right from the beginning [1].

For, on the one hand, the human ear is continually changing in the extent to which it is capable of accepting and thinking sound; on the other, the acoustic environment man lives in changes, instruments are modified, new materials and instruments are produced. Suffice it to say that Chopin, whose work was almost entirely dedicated to the piano, had never heard the modern piano on which his music is played today which produces very different sounds from the instruments of his day [2].

The musical score itself is only an approximation, it cannot contain all the indications necessary in theory to indicate unequivocally how it should be played. For example, only summary indication can be given as to how expressive the musical discourse should be.

Consequently interpretations are always different, not only in different eras, and when performed by players, but also for the same performer too, depending on the depth of his emotion and concentration. In the same way, the listener has different feelings at each performance.

But when the interpretations are recorded, we get something similar to the photographic image. The recording fixes that performance given in that precise historical moment, with those instruments, and it can be listened to over and over again and analysed over time recalling a multiplicity of knowledge and exciting different feelings each time.

Let us now come back to photographic representation. It has been pointed out that photography can be not only a figurative art capable of representing the visual reality of the world but also a real language of communication. This means that by the creation of images, we can not only represent and communicate aspects of the visual reality around us but also express concepts that go far beyond the specific content of that image.

Figure 1 is an example of this. This image shows part of a skyscraper lit up by the sun: every window reflects the same image of a detail of the skyscraper opposite but distorts it in a different way, thus expressing concepts which would take many words to express in verbal language. In short, each of us filters the reality in which we are immersed in our own way; everything is subjective. Perhaps the 'truth' lies in the sunlight, but nothing can be made out there anymore, and so man is not allowed to reach it, everyone is prisoner of his or her own individual truth. Pirandello wrote many works to get these concepts into focus.

Figure 2 represents another example of the expression and communication of concepts. There are two different types of geometrical pattern in this image, the one, Euclidean and sail-like, and the other, fractal and cloud-like: Euclid and Mandelbrot, separated by about 2000 years, in the same image.

So, having seen in general how photography is an instrument for representing reality and a language of communication, we can now look at aspects concerning the creation of the image itself, going into greater detail especially regarding points connected with how to catch light [3], how to choose the frame and the potential effects of the various angles from which the photo can be taken and lastly taking into consideration some geometrical structures and the communication of feeling. 


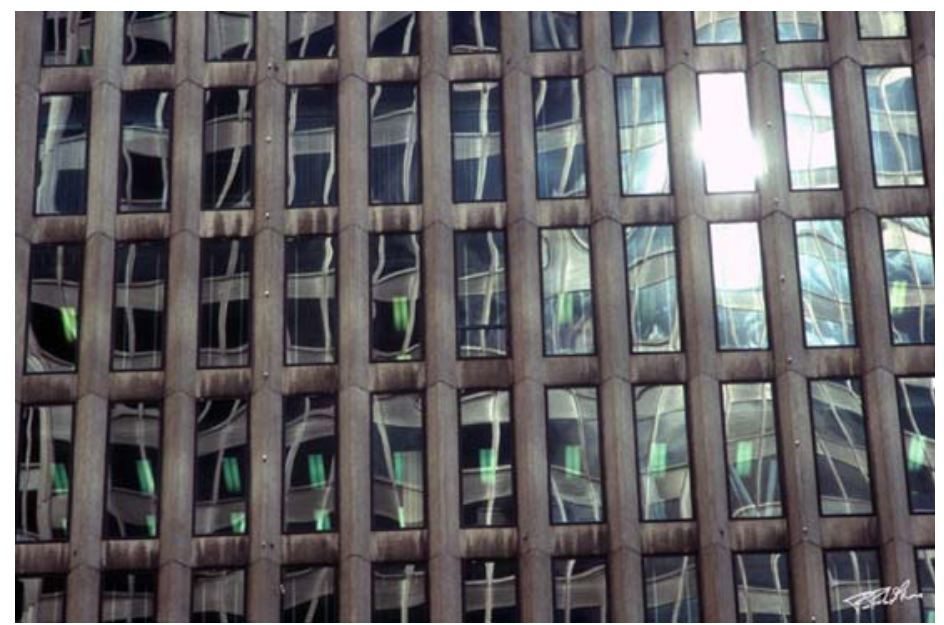

Figure 1: 'Pirandello'.

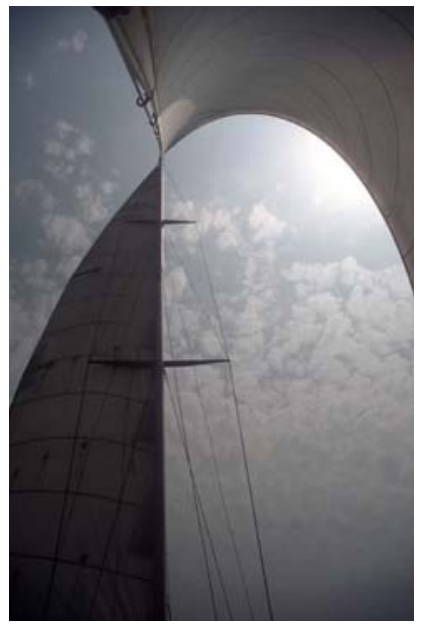

Figure 2: Sailing.

\subsection{Light}

Light creates the world we perceive around us and, according to how the photographers capture it, they can make something beautiful, a work of art, or a commonplace, unmeaningful image.

Playing with light, choosing the best moment to take the shot, choosing the frame that enhances the subject, bringing out its hidden geometric structures, exploiting the contrasts between light and dark areas: in photography it all depends on learning to capture light.

So let us begin with the main sources of light and then observe the images that the light forms, particularly those that it creates by interacting with elements that are interesting and stimulating for the photographer, such as water and glass.

\subsubsection{Sources of light}

The sun, the moon and the stars are the main sources of light which shines on our world. So the wish to represent them in images arises spontaneously.

Almost everyone must have tried to take a photograph of the sun, especially at dawn or sunset, when it is low on the horizon and easier to look at. Its light creates intense, romantic effects, the play of oblique light and shadow gives depth and fullness to the scene framed (Fig. 3).

In other cases, the sun may become the main subject of the photograph taken, whoever to include or exclude direct sunlight may lead to the creation of very different images (Figs. 4 and 5), even though they are taken in the same place at the same time [4].

The stars, too, can create fascinating images. As they attempt to represent them, the photographers can even capture things not visible to the human eye, which yet give a sense of the magic of the night sky.

By directing the camera northwards and leaving the shutter open for a long time, you obtain an image with circles described by the stars as a result of the earth's rotation. They are circles of various colours concentric with the Northern star. Hale-Bopp appears rotating with its tails too [5].

By choosing a suitable exposure time, after trial and error, the landscape framed can also be lit up, while leaving the impression of a night sky. In Fig. 6 the time of exposure was almost $1 \mathrm{~h}$. 


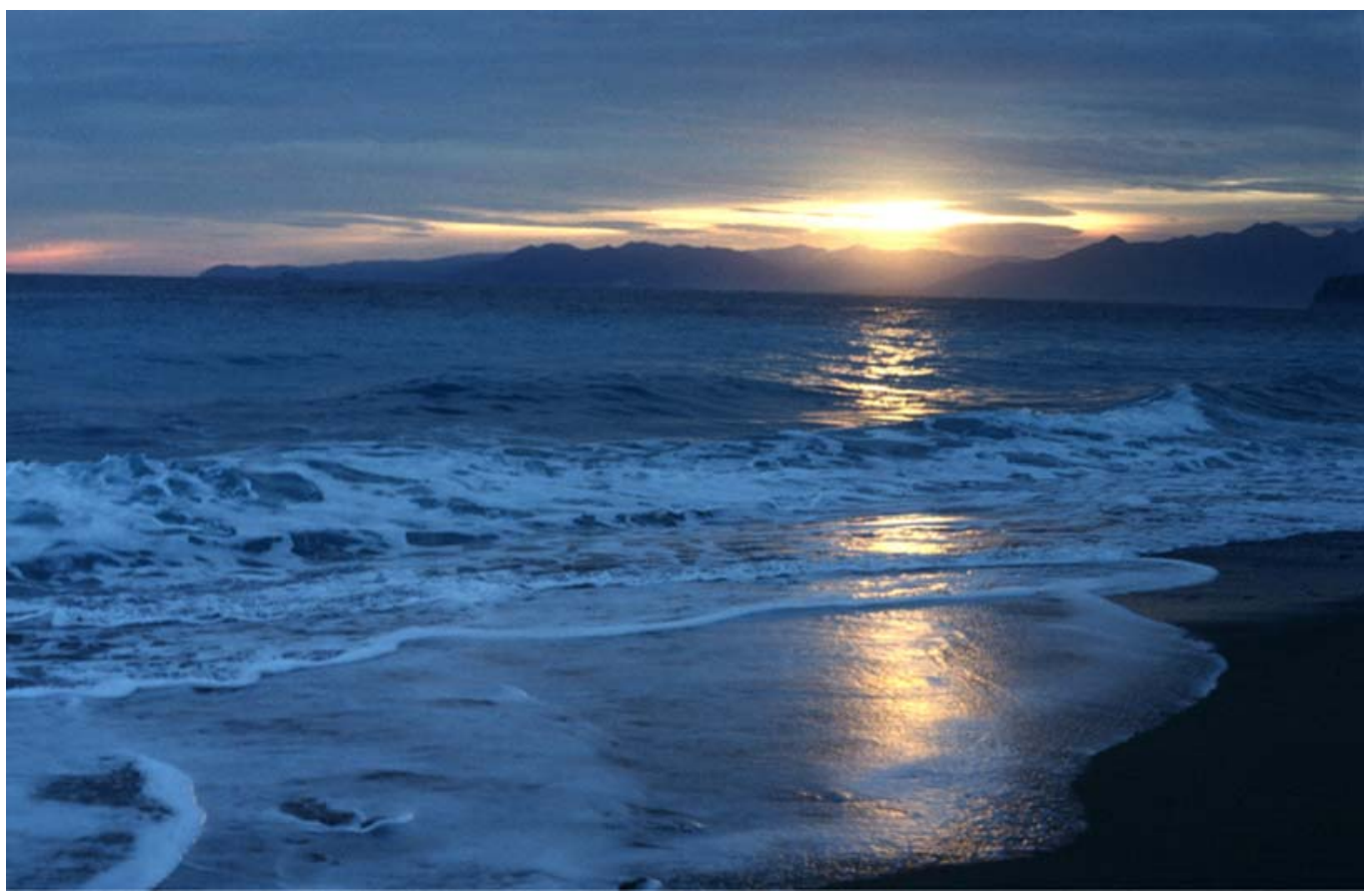

Figure 3: Sunset at Varigotti, Italy.

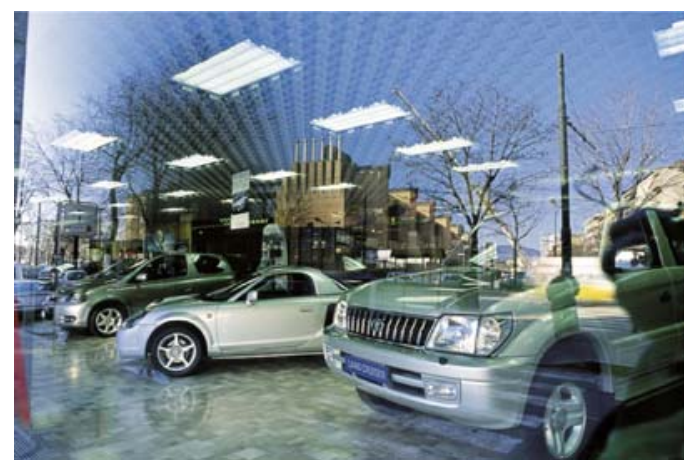

Figure 4: Turin, Italy.

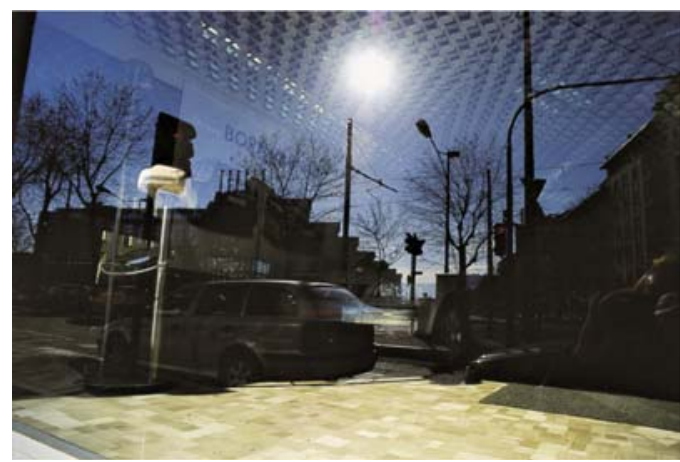

Figure 5: Turin, Italy.

The moon sends us a reflected light, but perhaps precisely because of this it is very fascinating and mysterious (Fig. 7). The exposure time is much shorter here and the circles of the stars become small segments [5].

\subsubsection{Light and water}

Light, interacting with water, especially creates picturesque images, for example, when it plays even on small waves, as they lap the top of the anchor of a boat, slowly rocking (Fig. 8), or a swan swirling round in the water (Fig. 9) to create a broken-up reflection. Images like this last no more than a second; they must be caught in passing: a second later they no longer exist. 


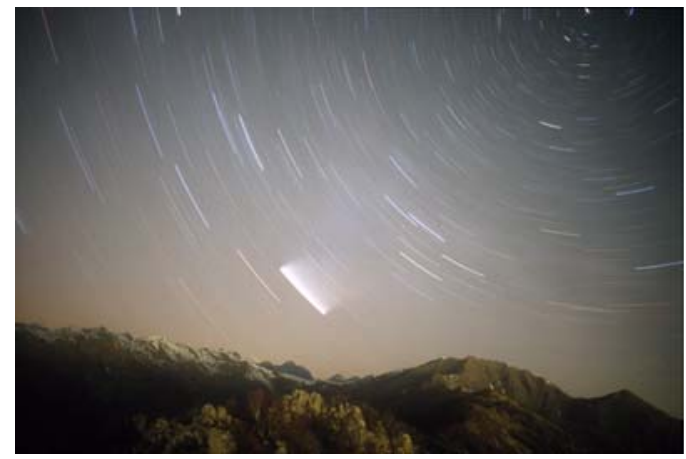

Figure 6: Hale-Bopp comet, Susa valley, Italy.

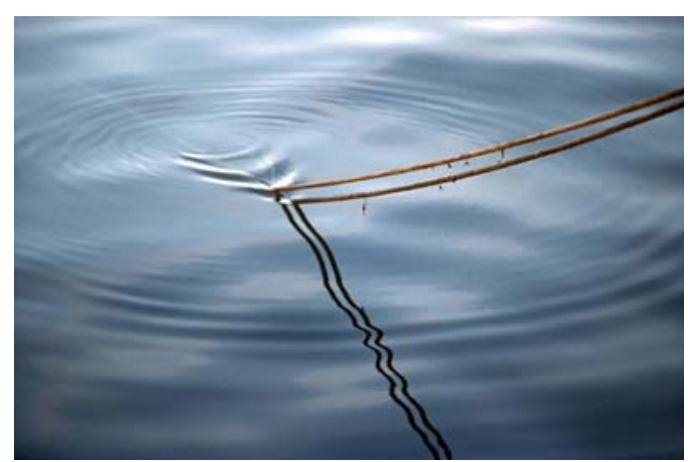

Figure 8: Waves, Capri, Italy.

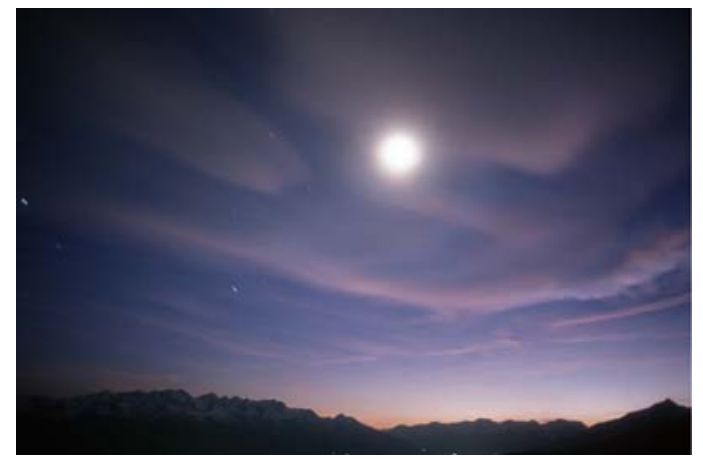

Figure 7: The moon, Susa valley, Italy.

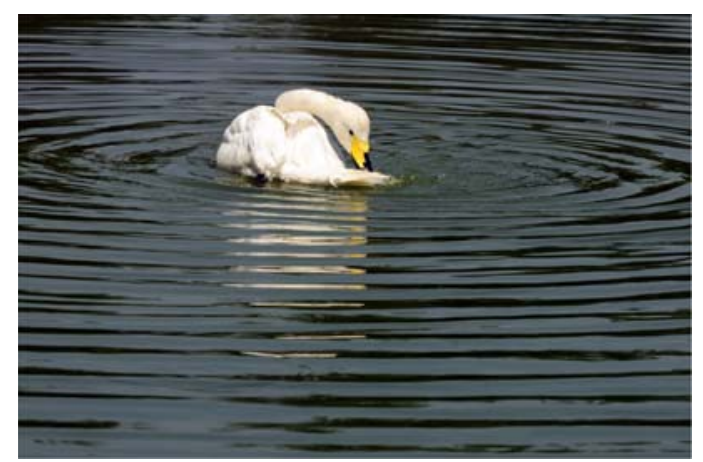

Figure 9: Swan, Racconigi, Italy.

At other times, mainly in puddles, the light creates dream-like surreal images, which produce very interesting and complex effects. The photographer can play not only with the images reflected in the water but also, for example, with the ground under the water, objects that may be floating on it and with its fanciful geometric shapes. Therefore, the photographer has to take into consideration light, reflected images, transparencies and geometry all at the same time.

Sometimes puddles can break up reflections creating geometrical harmonies and fascinating atmospheres (Figs. 10 and 11). In other cases, almost surreal situations can be caught by including non-reflected zones in the frame (Fig. 12).

Often it is interesting to turn images upside down [1], obtaining new unusual fascinating effects (Figs. 13 and 14). In this image, the triangle is the geometrical feature that gives it unity. It is repeated everywhere, in the structure of the cranes, in their position, in the car-park signs and the form of some of the puddles.

\subsubsection{Light and glass}

Through glass, perhaps more than through water, light can create wonderful, incredible but real images. Light passes through the glass, which reflects it and breaks it up into two superimposed images which the observer does not generally look at together. Yet, if we try to observe the resulting image, in the streets of a town, for example, where there is glass almost everywhere, we get a new 


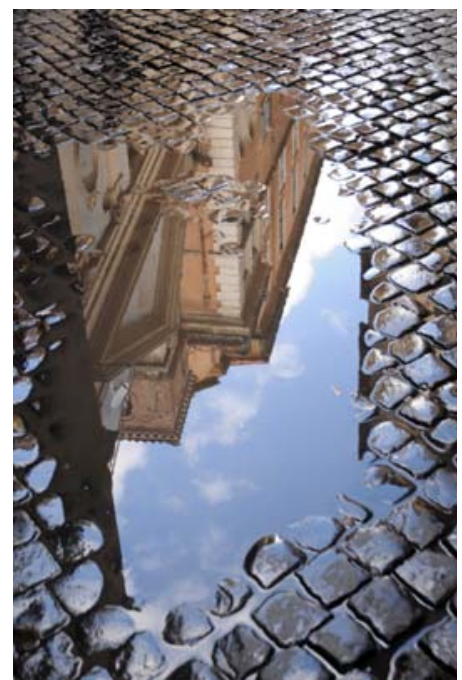

Figure 10: Rome, Italy.

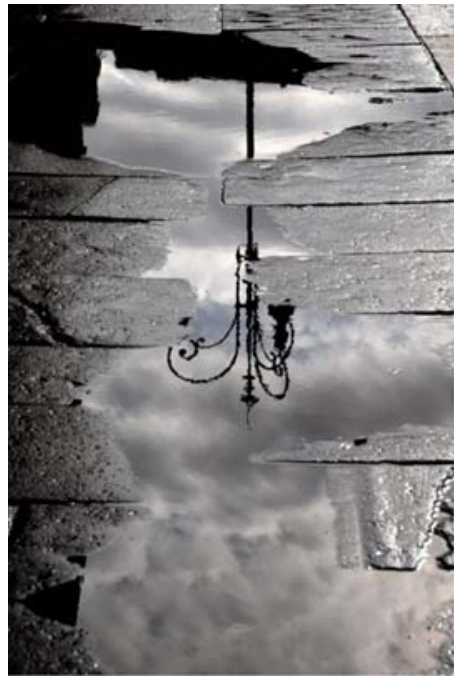

Figure 11: Rome, Italy.

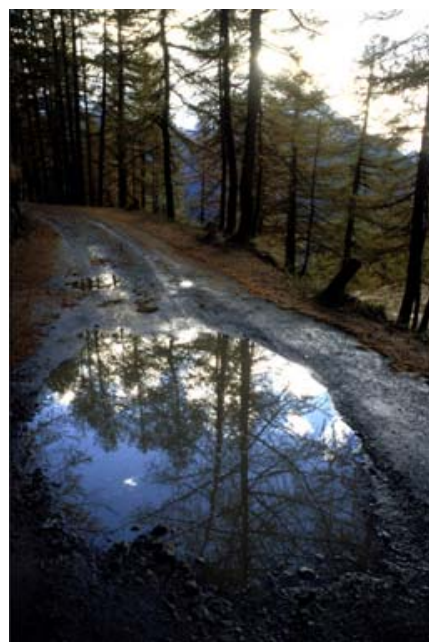

Figure 12: Val Chisone, Italy.

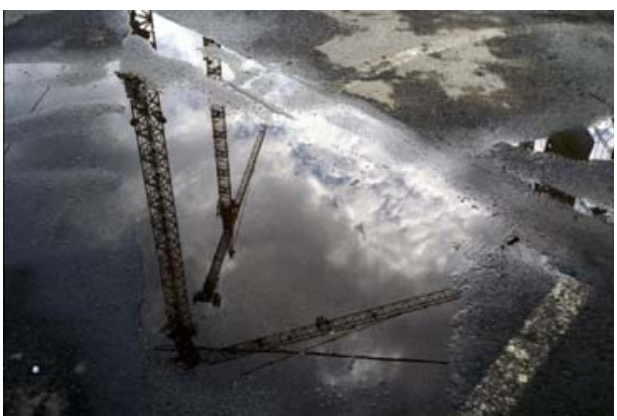

Figure 13: Berlin, Germany.

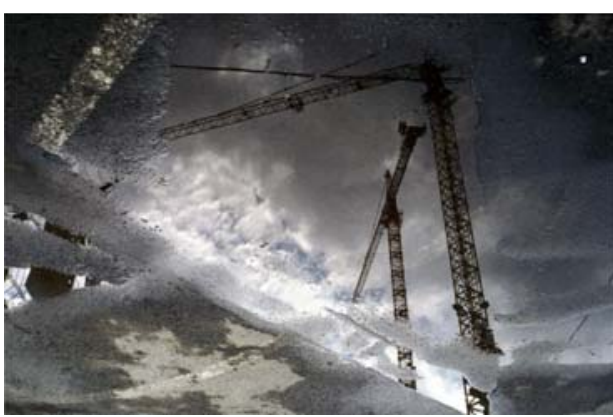

Figure 14: Image turned upside down.

townscape and discover images that generally escape most people and which can be caught directly and easily by the camera, without any further elaboration.

Anyone strolling along the streets of a town or a village can watch and enjoy the lights, the shapes and the colours forming wonderful images. Although at first sight they may appear fictitious and obtained through complex techniques, these surreal and sometimes dream-like compositions, almost an abstract play on shapes and colours, are in fact simple images of reality captured through the lens of a camera, single shots taken while observing, maybe with a touch of irony, the townscape surrounding us. As we look at these images, we realize that reality can be more fanciful and unpredictable than any kind of imagination. Let us consider some examples:

Reflected houses and objects on show in the shop window, framed very accurately, give a single harmonious image both in form and shade of colour (Fig. 15).

In other cases, the image looks almost like an Impressionist painting [4]; the reflection of a square in pale sunlight and the transparent embroidered white curtain gathered behind the windowpane create this effect (Fig. 16). 


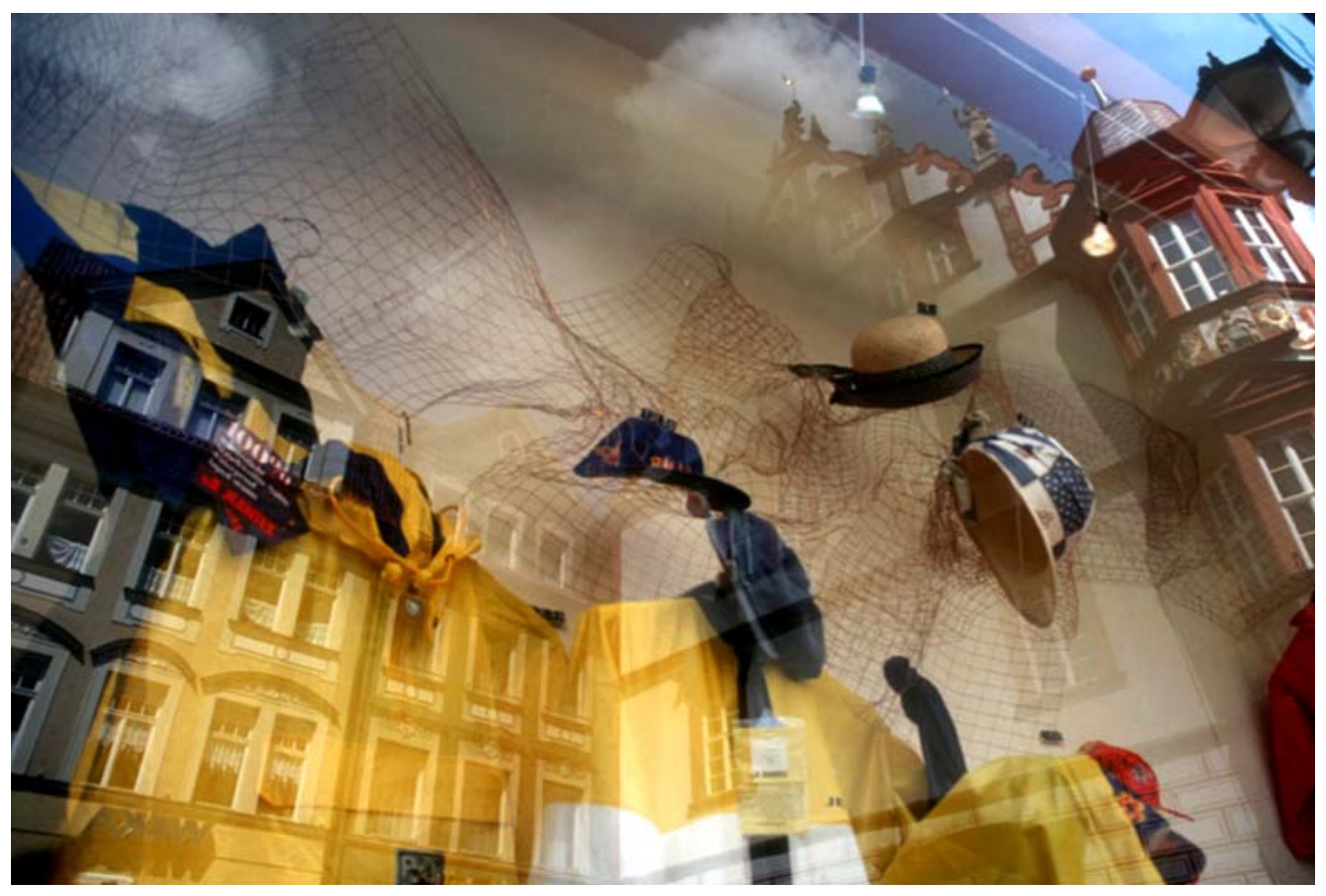

Figure 15: Coburg, Germany.

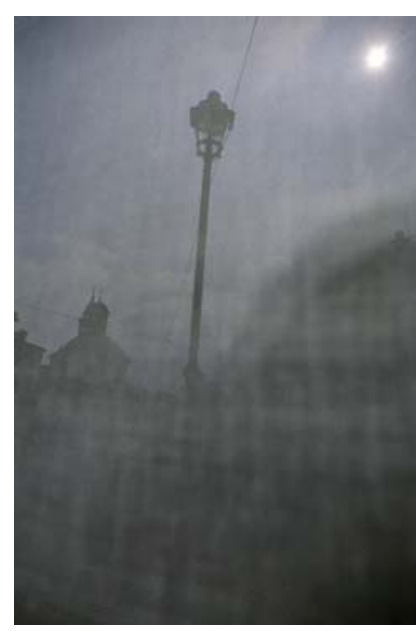

Figure 16: Turin, Italy.

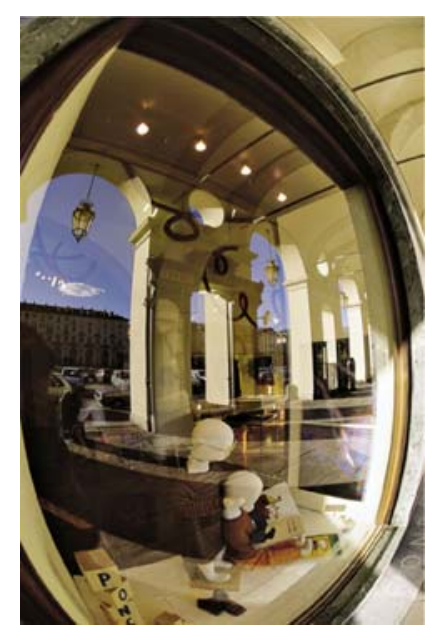

Figure 17: Turin, Italy.

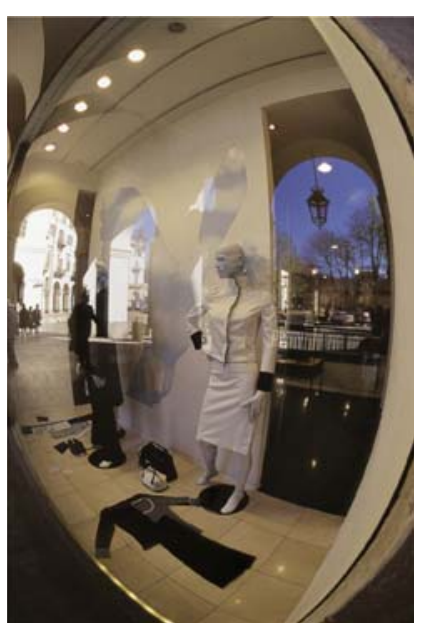

Figure 18: Turin, Italy.

Finally, by using a fish-eye lens [4], the whole shop window can be included in the image so that the overlapping vision seems like that of a TV set (Figs. 17 and 18).

It may be useful to conclude with some parallels with paintings. With a small effort and, of course, taking the due proportions into account, we could say that the photo in Fig. 15 brings to mind the atmospheres in Dali's paintings, the one in Fig. 16, has already been pointed out, has something of 
the French Impressionists, while that in Fig. 18 evokes the atmospheres of Magritte. Perhaps photography can really bring us near to painters and their way of representing and interpreting reality.

\subsection{Framing a photograph}

To frame the scene, to define the outlines and limits of the reality we wish to catch, together with the art of catching the light, constitutes the fundamental element in creating meaningful and beautiful images. The photographers can make many different choices. They can take a widespread scene and discover minute details in it and as they define the slice of reality that interests them, they can bring out harmony of line, geometrical forms, areas and colours. Thus, they can interpret in their own way the world around them and basically reveal their own self.

In these ways of representing reality, the photographer is greatly aided by the variety of lenses available to him. And today, with the advent of the digital camera, new possibilities are being opened up as the photographers can decide the format of the image they have in mind with even greater freedom and ease.

\subsubsection{Lenses}

Man's perception of reality depends on his senses and so even the visual perception of reality is not objective or absolute. It is distorted insofar as it depends on our eyes and on how wide a field we can take in at a glance. By using the camera, we increase our own powers of observing reality, distorting it in many different ways and varying the extension of the shot being taken according to the focal lengths we are using, ranging from the fish-eye to the most powerful telephoto lenses. So every lens becomes a new eye to see with; however, it is important to be aware of the specific powers of every new 'eye', so as to use it to the best effect and discover the aspects of reality that that 'eye' is able to see. We can now pause briefly to examine some of these characteristics, starting from the shortest focal lengths and concentrating particularly on ways of exploring them so as to create beautiful and meaningful images.

The fish-eye lenses $(<20 \mathrm{~mm})$ : the distortion this focal length produces is very different from that of the human eye; the curving of the straight lines becomes more and more pronounced, the further we get from the centre of the scene. This enables us to emphasize sensations we feel in the place where we are taking the photo, for example, to feel enveloped in the interior of a church, such as St. Antimo, in Tuscany, Italy (Fig. 19), or in an ancient village, Calcata (Fig. 20) near Rome, or it enables us to bring out fantastic geometrical forms such as those in the hoisted sails of a catamaran (Fig. 21) or it can emphasize the feeling of oppression we get when the clouds in the sky (Fig. 22) loom over us.

Or, in the case of wide landscapes, the curve of the horizon reminds us that we live on a globe, as in Figs. 23 and 24.

The wide lens ( 21 to $28 \mathrm{~mm}$ ): perhaps these are the lenses which best catch real sensations, though their focal length does not correspond to that of the human eye. Actually it enables us to place a subject in its setting so that we can perceive this all-over reality more clearly. First, of course, we need to identify a subject in the foreground, taking into account that this focal length makes it seem nearer to us than our eye does; then we must choose the best frame for its surroundings, which will seem further away than when we look at them directly.

Here are a few examples: a boat drawn up on a beach in Liguria, Italy (Fig. 25) and a flock of sheep along the shore of a little Alpine lake in the French Alps (Fig. 26).

The lenses with focal length corresponding roughly to that of the human eye (about $50 \mathrm{~mm}$ ): geometrically the slice of reality corresponds to that of the human eye, but the sensations we feel 


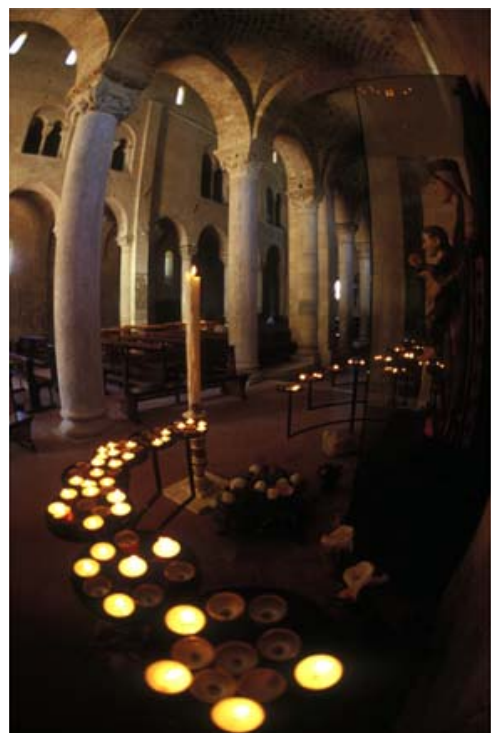

Figure 19: St. Antimo, Italy.

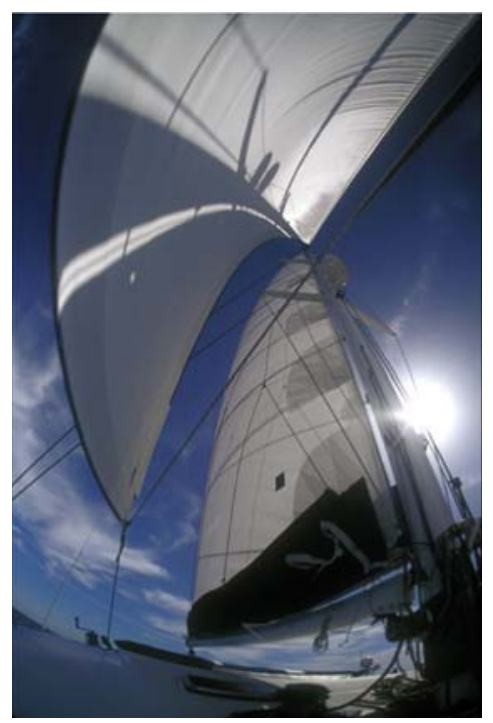

Figure 21: Sails.

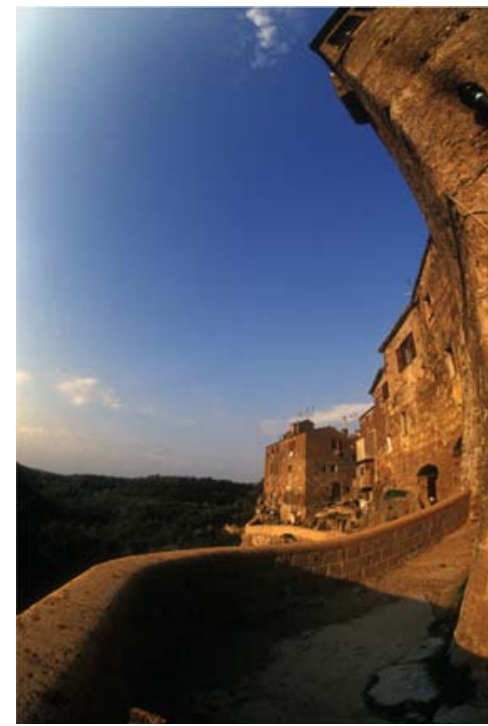

Figure 20: Calcata, Italy.

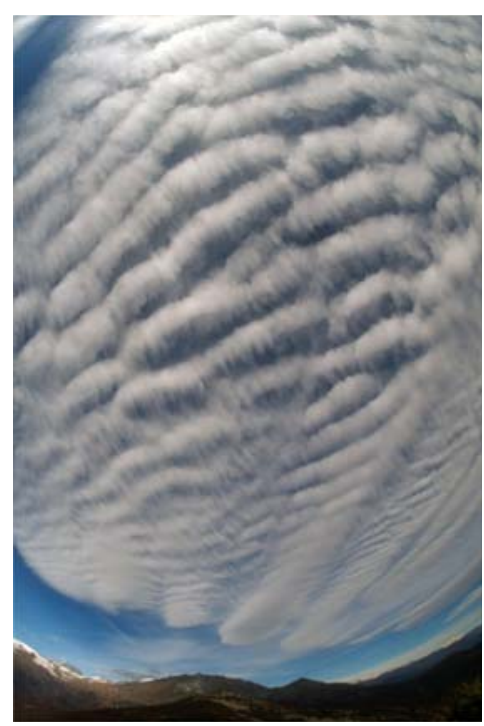

Figure 22: Clouds in the sky.

in the real world do not seem the same as those aroused by the corresponding photographs. Perhaps the wide lens gives us the perception of the reality that comes through the eye best of all, even though the focal lengths are different.

The telephoto lenses (about $80-1000 \mathrm{~mm}$ ): the slice of reality grows nearer, as we gradually increase the focal length, and as it grows larger we see the details of the image more clearly, bringing details near when they are not near in reality, as with the seagull and birds in flight in Figs. 27 and 28. 


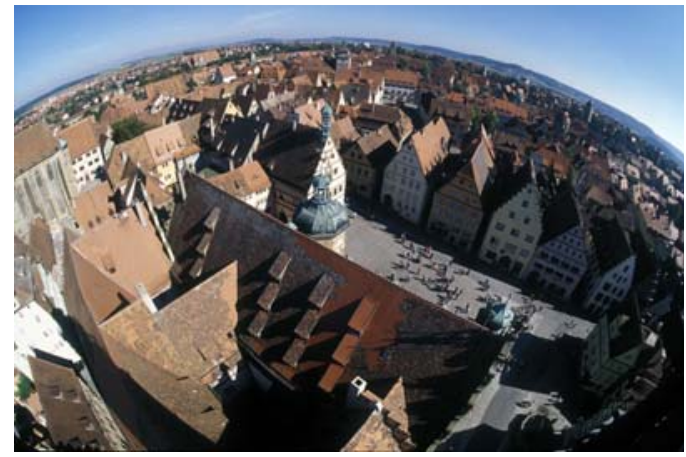

Figure 23: Rothenburg, Germany.

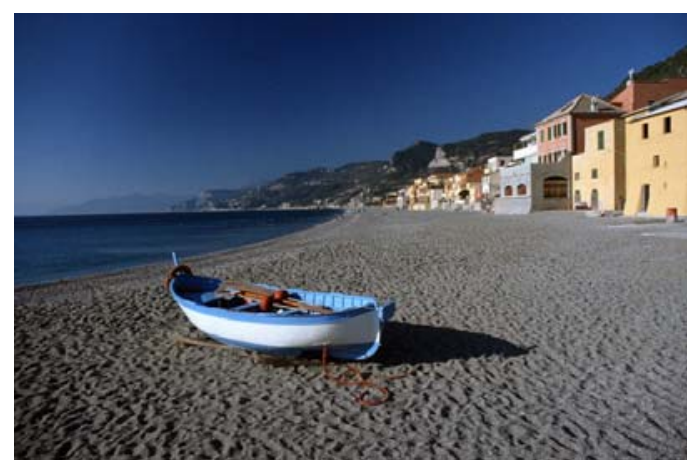

Figure 25: Varigotti, Italy.

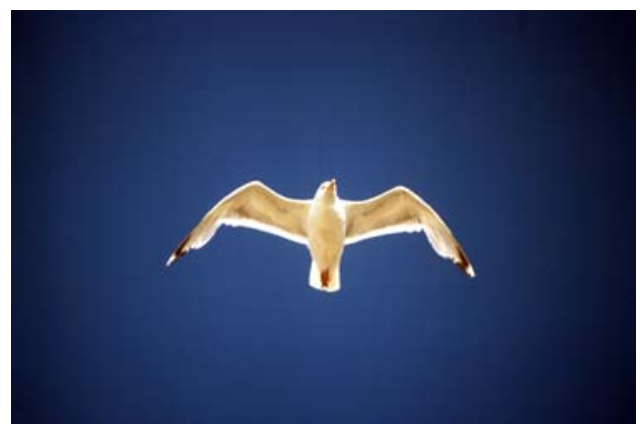

Figure 27: Seagull.

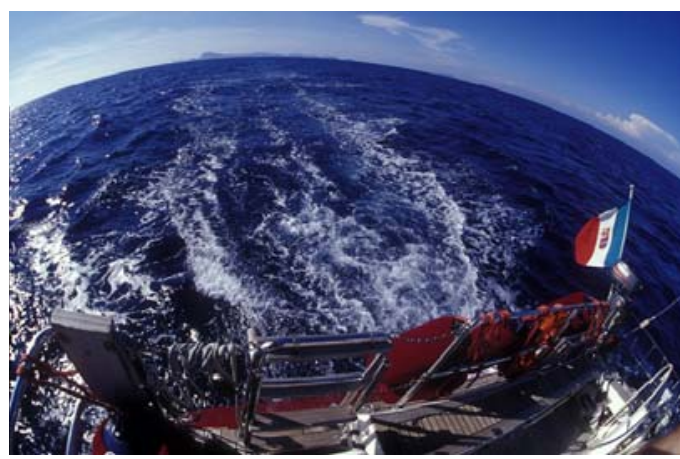

Figure: 24: Sailing off the island of Ponza, Italy.

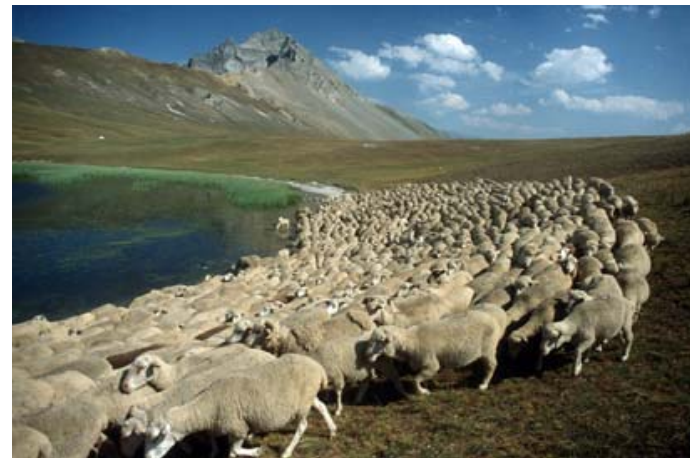

Figure 26: Lake Thures, France.

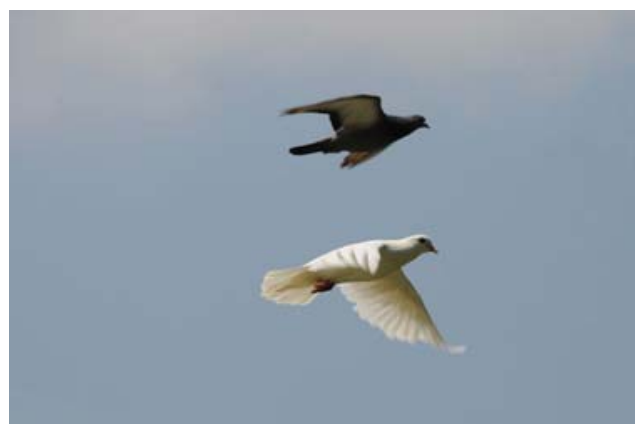

Figure 28: Birds.

The effect that the photographers can play on best as they create their images lies perhaps in their skill in exploiting the way telephoto lenses can bring the planes of a scene nearer together, just the opposite of the way the wide lens can push them further apart.

An example is the image of Fig. 29, taken with a $1000 \mathrm{~mm}$. lens: here the sun is captured at dawn, just above the chimney of a house, composing something like an enormous 'lampshade'. But the chimney is $200 \mathrm{~m}$ away, the Basilica about $10 \mathrm{~km}$ and the sun infinitely further. Yet, everything seems to lie on the same plane; the depth of the scene has been wiped out. 
Macro-lenses: these are lenses that enable us to observe and enlarge objects of very small dimensions so that we can see details not perceptible to the naked eye and discover unknown worlds.

Here are some examples: a praying mantis (Fig. 30), edelweiss (Fig. 31), a weird pinecon (Fig. 32), a kitchen brush (Fig. 33).

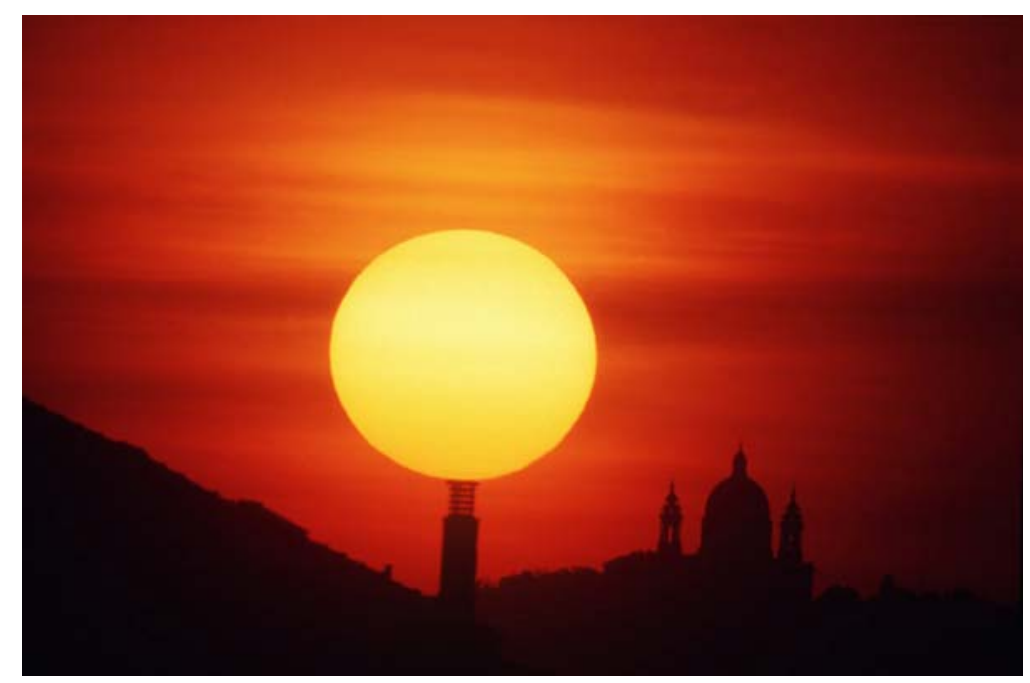

Figure 29: The 'lampshade', Turin, Superga, Italy.

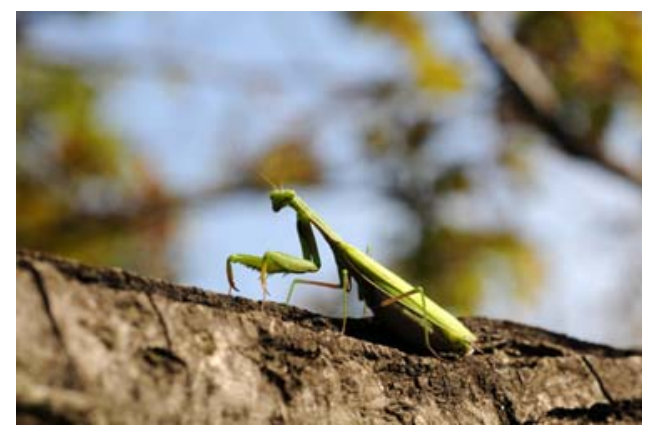

Figure 30: Praying mantis.

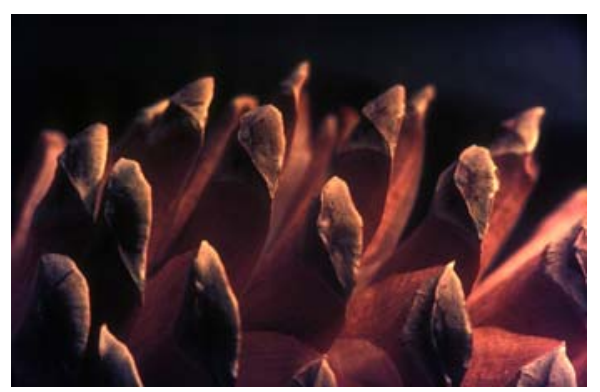

Figure 32: Weird pimecon.

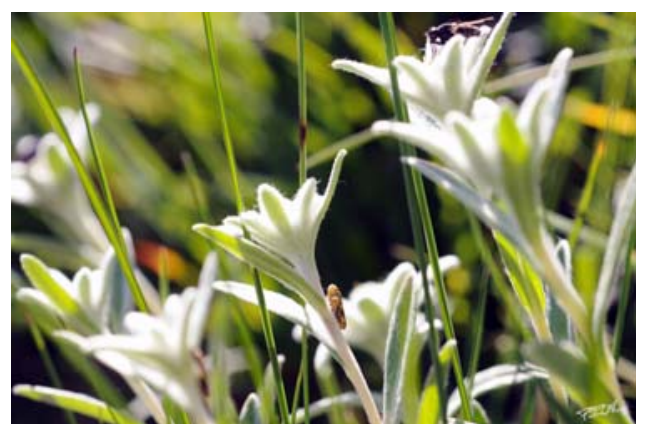

Figure 31: Edelweiss.

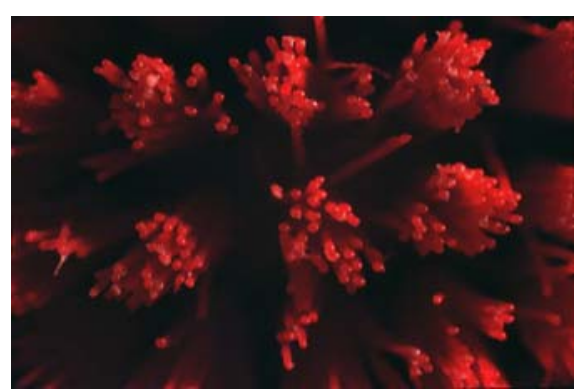

Figure 33: Kitchen brush. 


\subsubsection{Free format}

The fixed format of the photo film, $24 \times 36 \mathrm{~mm}$ or $6 \times 6 \mathrm{~cm}$, has always been a limitation to the choice of frame. Like all limitations, it is a constriction and at the same time it spurs the photographer to exploit it to bring out the idea of the frame chosen more clearly. It constitutes a problem that must be solved but in solving it one can obtain a better result.

However, there are situations in which the photographer would like to free himself from this limitation, especially when the subject could be represented to greater effect, better expressing the feelings it could communicate if the format could be chosen freely.

This situation often occurs in the case of landscape. For example, a long chain of mountains, a stretch of coast, tree-lined avenues could be represented in horizontal, long, narrow images, while waterfalls and trees could be more effectively rendered by tall, vertical, narrow images. In this way, the photographer could do justice to their beauty and communicate more intensely the sensations and emotions one feels before vast horizons or towering wonders of nature.

Digital photography has opened up great possibilities from this point of view, facilitating, albeit at the expense of long, painstaking work on the computer, the fusion of many shots into a single image, where each shot corresponds to a small area of the scene represented. Besides which it is now easy to improve the quality and definition of the images at will, choosing a suitable number of partial shots, to produce very large pictures.

In the following examples each image has been obtained by assembling 20 to 40 shots. These are high definition shots from which large-scale pictures can be printed, sometimes measuring several metres. They have been assembled manually because automatic software shows up the 'joins' too much.

Horizontal format (Figs. 34-42):

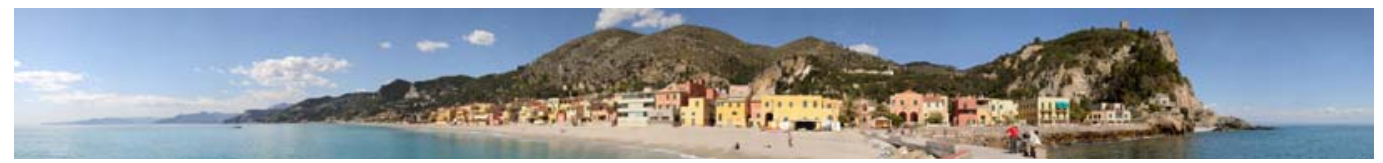

Figure 34: Varigotti, Italy.

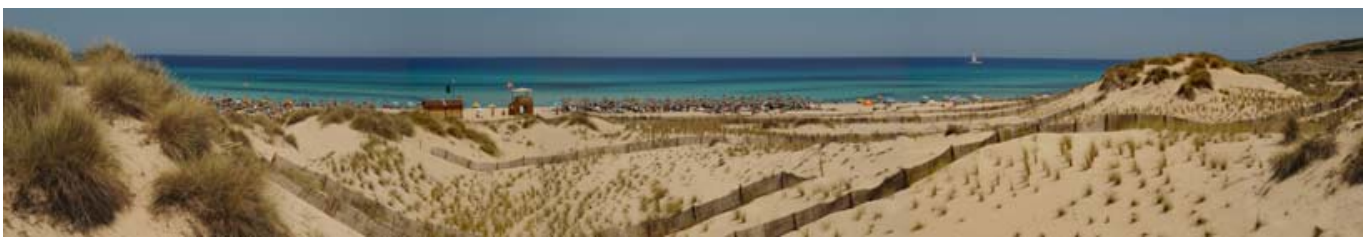

Figure 35: Majorca, cala Meschida, Spagna.

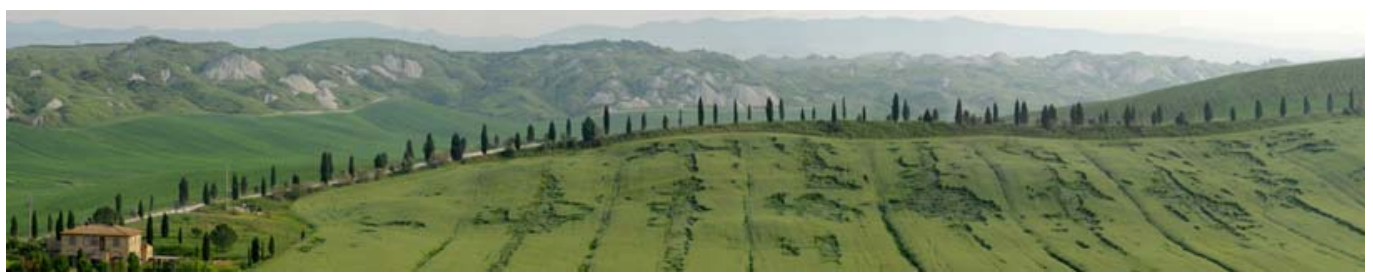

Figure 36: Tuscany, Italy. 


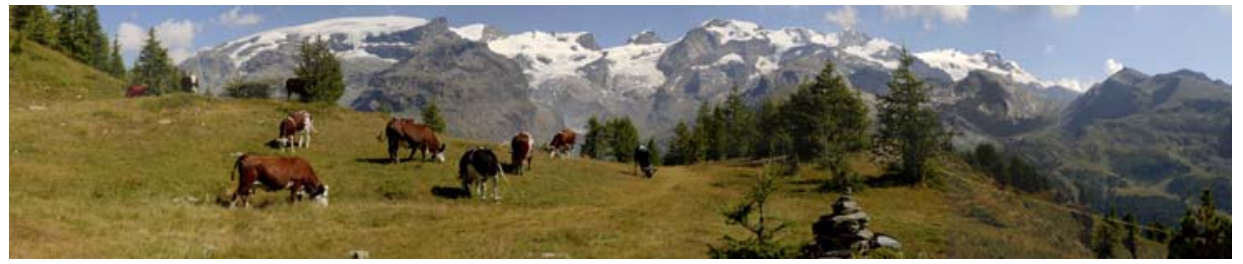

Figure 37: M. Rosa seen from the Val d'Ayas, Italy.

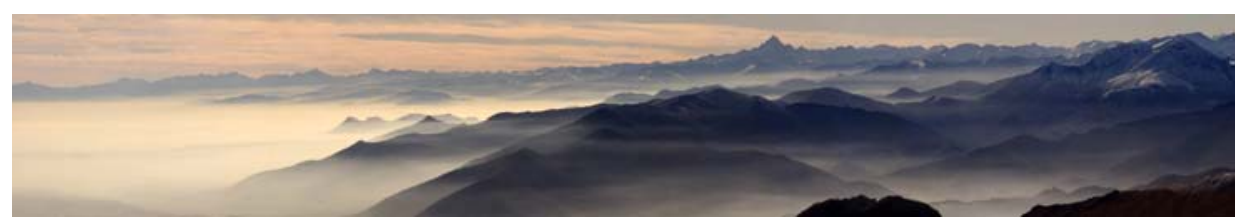

Figure 38: Monte Soglio, Piedmont, Italy.

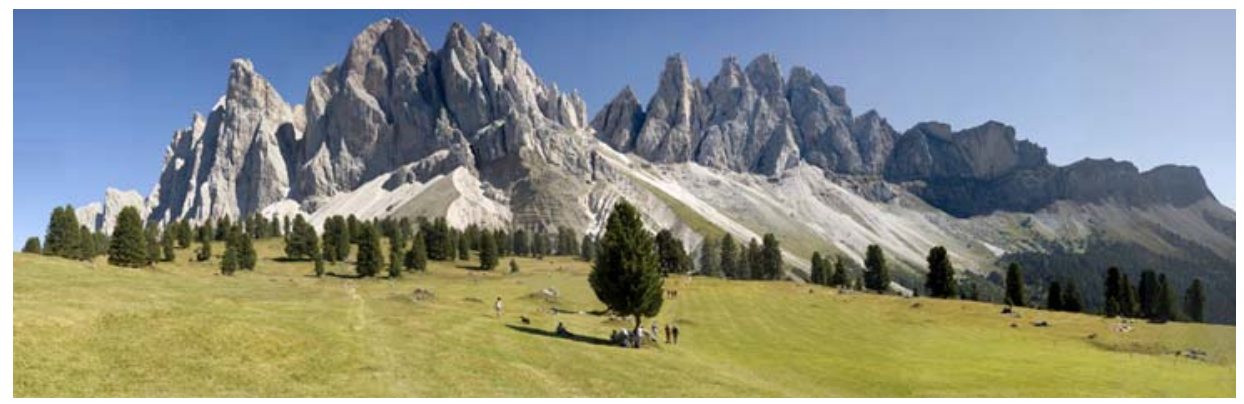

Figure 39: Dolomiti, the 'Odle', Italy.

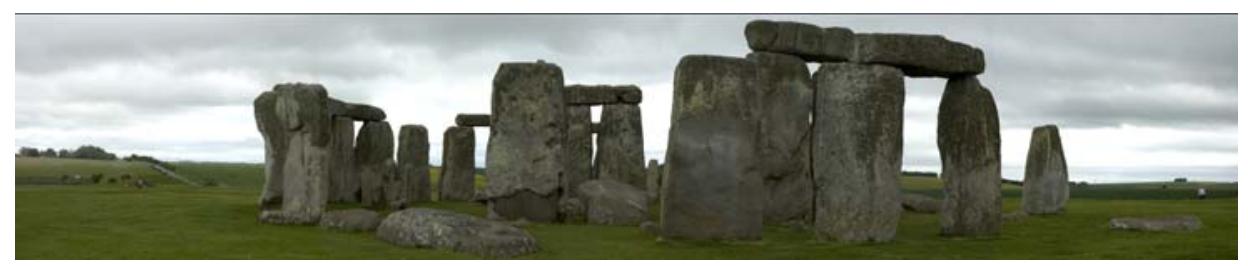

Figure 40: Stonehenge, UK.

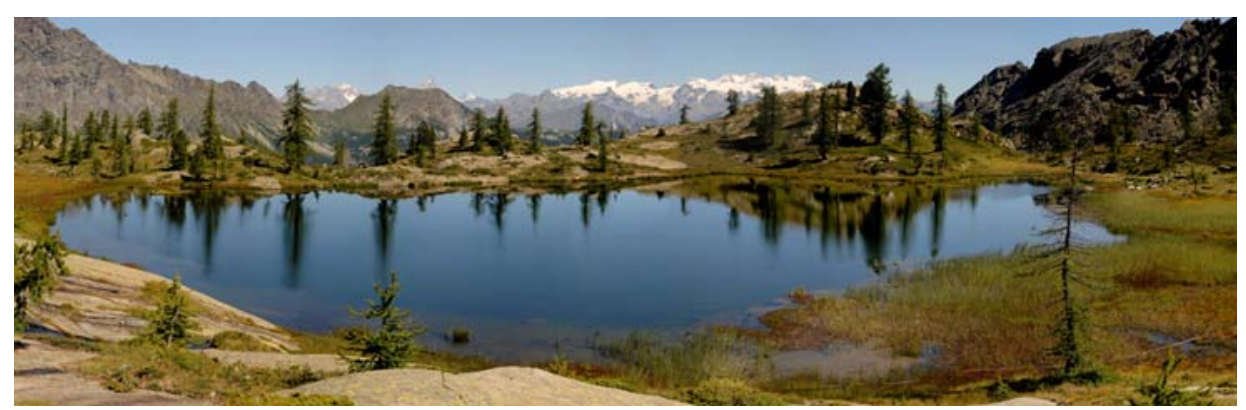

Figure 41: M. Avic Park, Lake Vallet, Italy. 


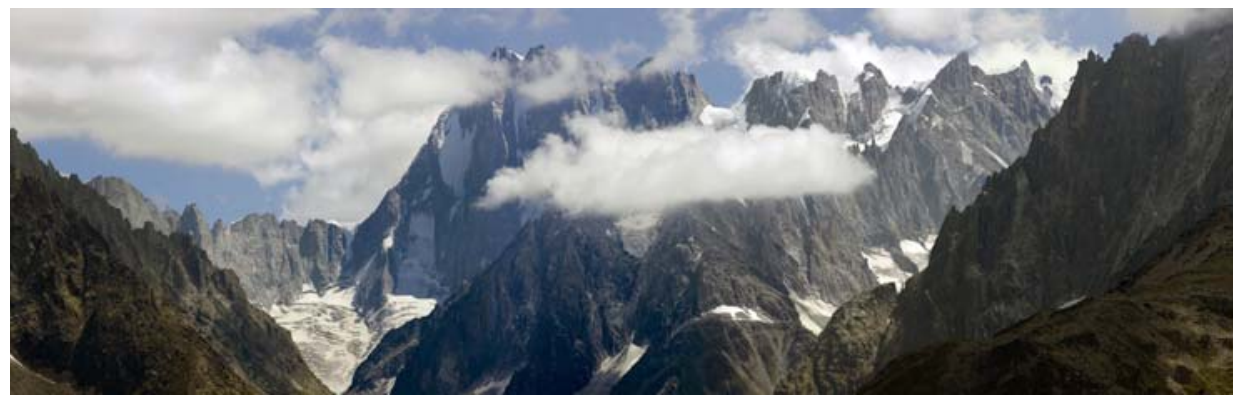

Figure 42: Grandes Jorasses, north face, France.

Vertical format:

- Figure 43: L'Alp d'Huez, France.

- Figure 44: Trees in Valnontey, Gran Paradiso Park, Italy.

- Figure 45: Loano seen from Verezzi, Italy.

- Figure 46: Lillaz waterfall, Gran Paradiso Park, Italy.

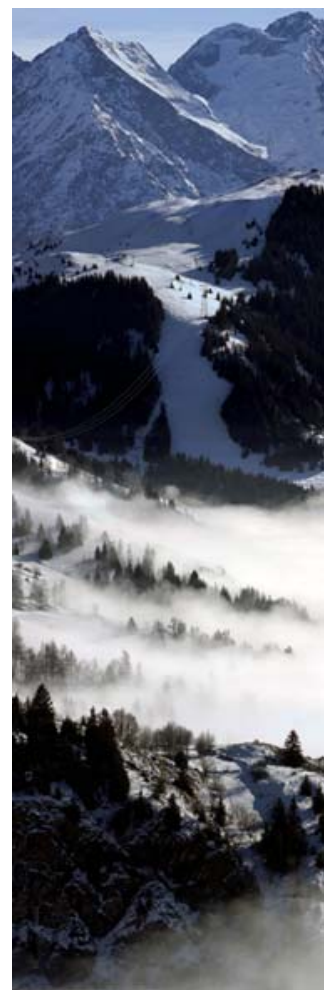

Figure 43

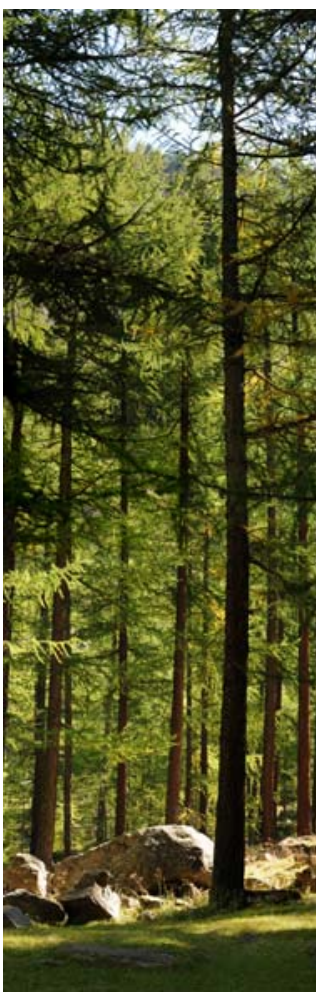

Figure 44

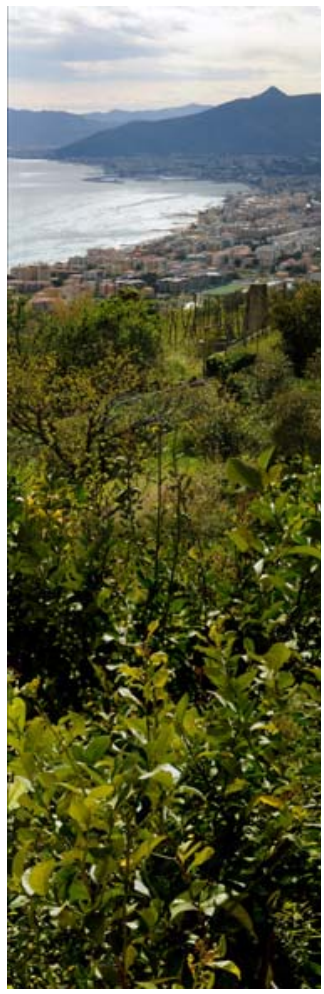

Figure 45

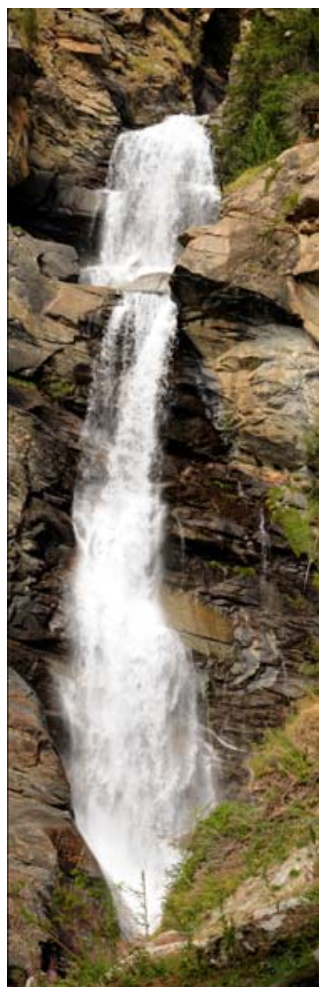

Figure 46 


\subsection{Geometrical forms}

Sometimes geometry can become the true subject of the image, revealing reality which seems abstract, yet is all real, with no distortion due to the effects of the lenses. A shot that marks out a slice of reality, transforming it into a pure, geometrical image, a harmonious pattern of straight lines, as in Fig. 47.

At other times, the photo reveals geometric forms that are hidden in the image, which only appear for a few seconds, yet the photographer's eye has managed to catch and highlight it by choosing an effective frame.

In Fig. 48, it is the shadow line, its continuation of the outline of the roof, which creates a geometrical form which will quickly disappear as the position of the sun changes.

In Fig. 49, the cow, as it grazes with its head turned left, takes up for a second a position in which the line of its backbone and its neck corresponds geometrically to the line of the mountain on the left in the background.

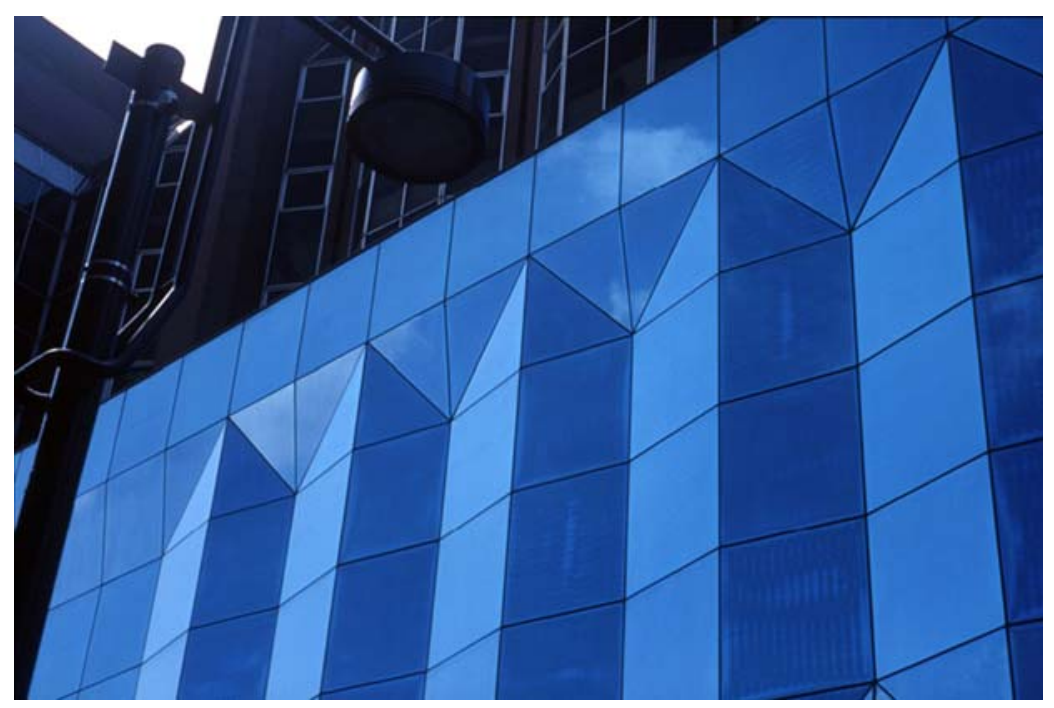

Figure 47: Leeds, UK.

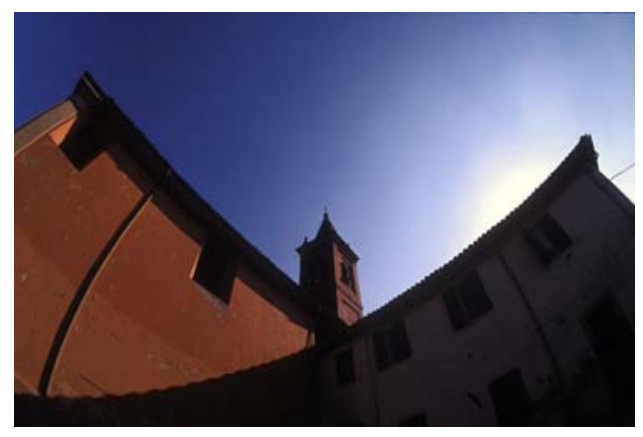

Figure 48: Surroundings of Bologna, Italy.

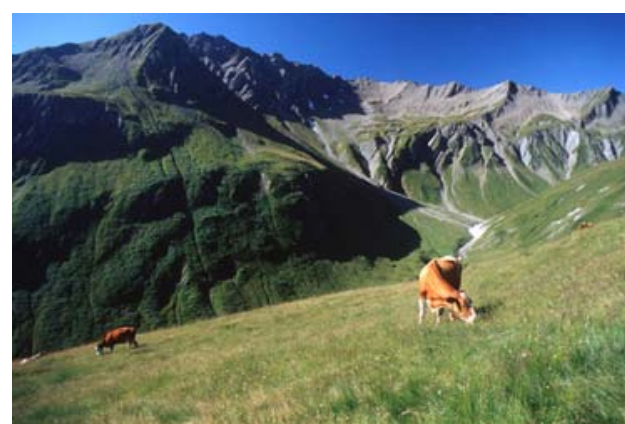

Figure 49: Val Ferret, Switzerland. 


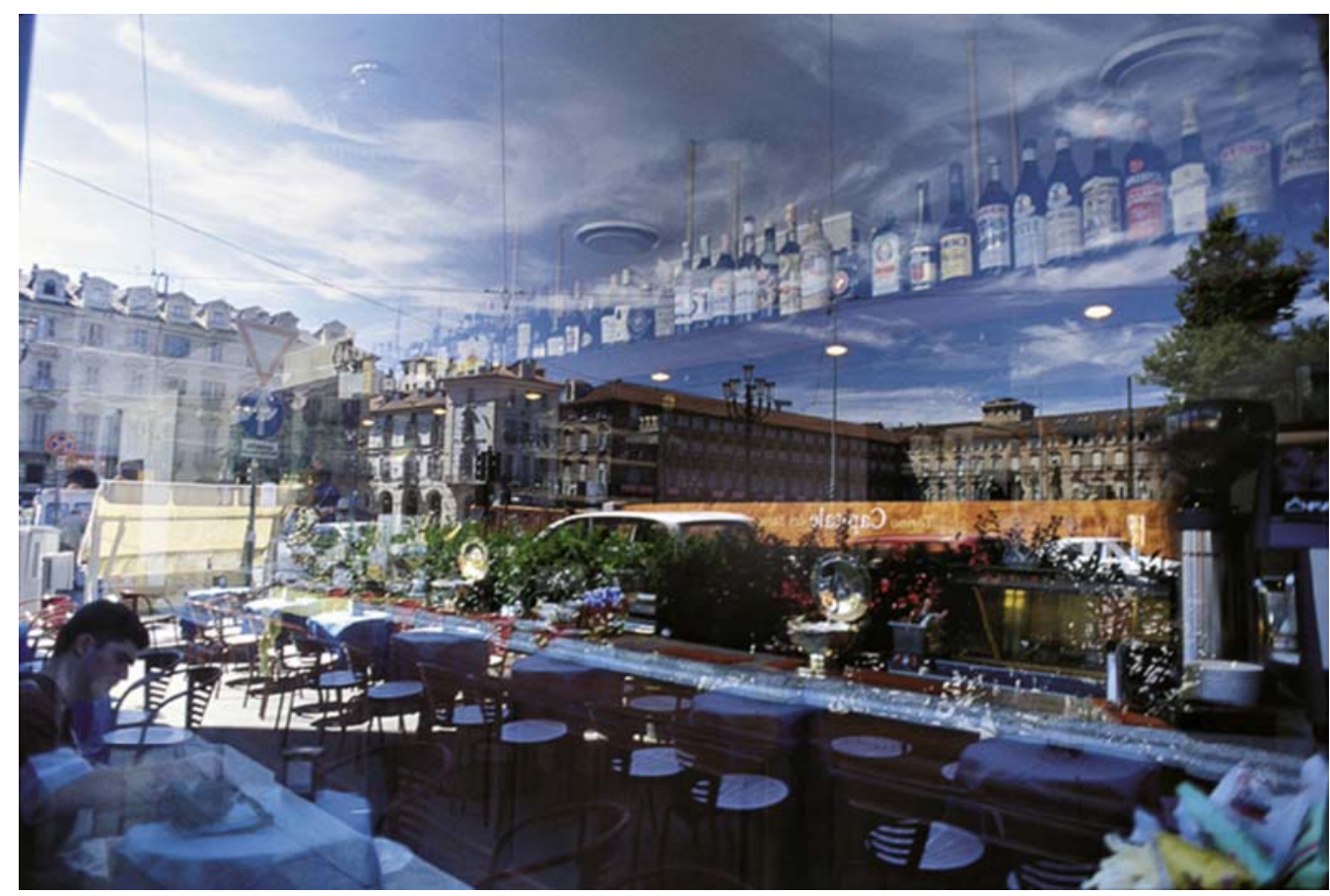

Figure 50: Turin, Italy.

In Fig. 50, a sheaf of diverging straight lines make up the hidden geometrical structure of this surreal image in which the row of reflected bottles against the skyline is above the outline of the roofs of the buildings. In this case too, this strange sight could have been seen by anyone passing through that square.

\subsection{Emotional experiences}

Emotional experiences that we may never have in our own lives may be discovered through photography. Yet the photographer who experiences them can try to transmit them to others by shooting meaningful images of them, as always, choosing the time of shooting with care and choosing the most suitable lens and framing to show us the reality of that moment.

This happens, for example, during adventurous excursions in wild natural settings difficult to get to, while we are climbing or sailing.

The climber-photographer tries to give an idea of the setting, a glacier (Fig. 51) or a vertical rockwall, of how you proceed in such a situation, for example, going up to Rocca Sbarua, in the mountains of Piedmont (Figs. 52 and 53) or coming down from the Southern Peak of the Tribola-zione in the Gran Paradiso group (Fig. 54).

When you are sailing, you get a sense of the infinite expanse of the sea, the strength of the wind as it moves the boat through the waves, you follow the manoeuvres on board. This is what the photographers try to catch and communicate in the pictures they take (Figs. 55-60). 


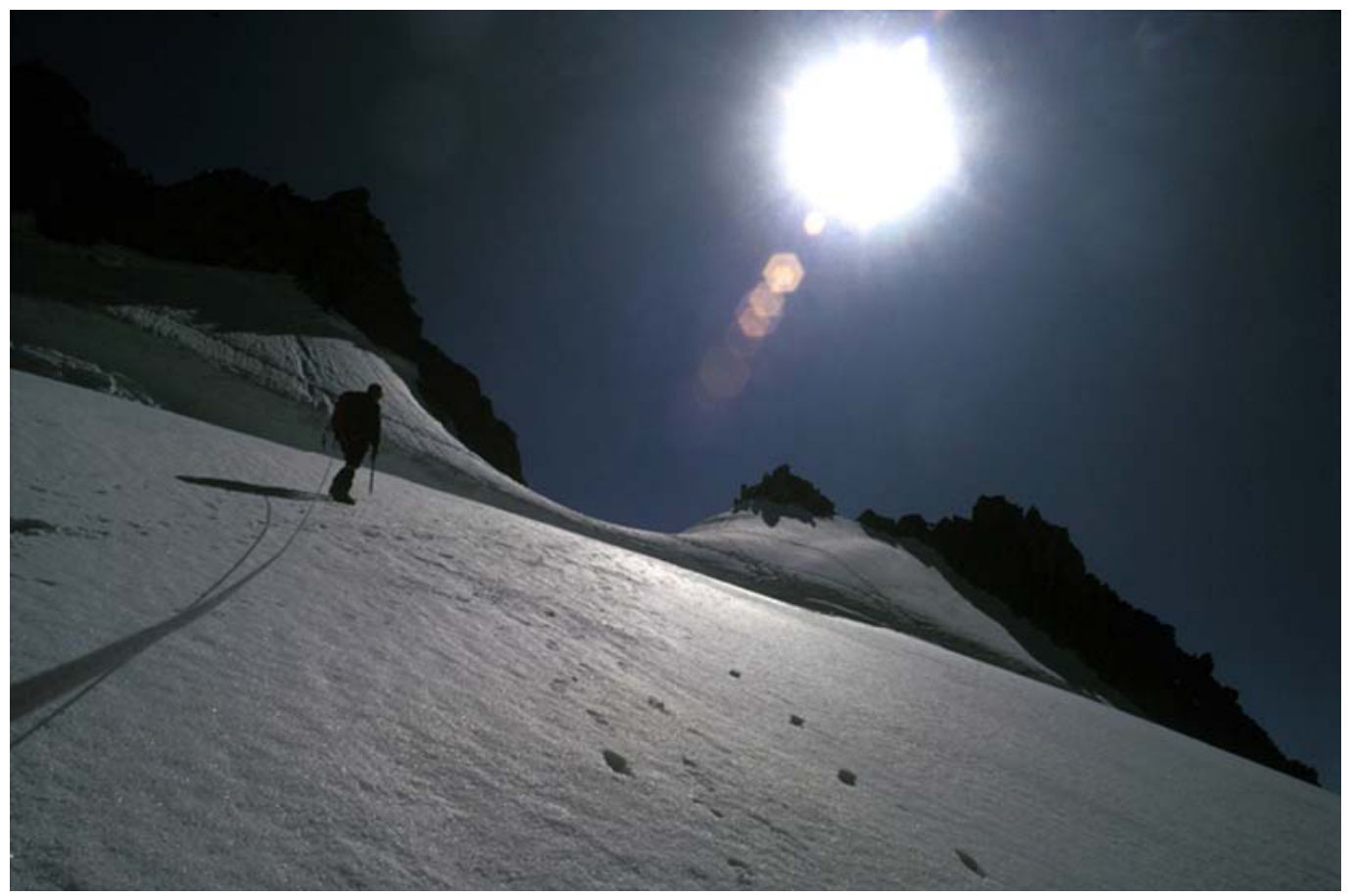

Figure 51: Mont Dolent (Mont Blanc group), towards the terminal glacier crevasse.

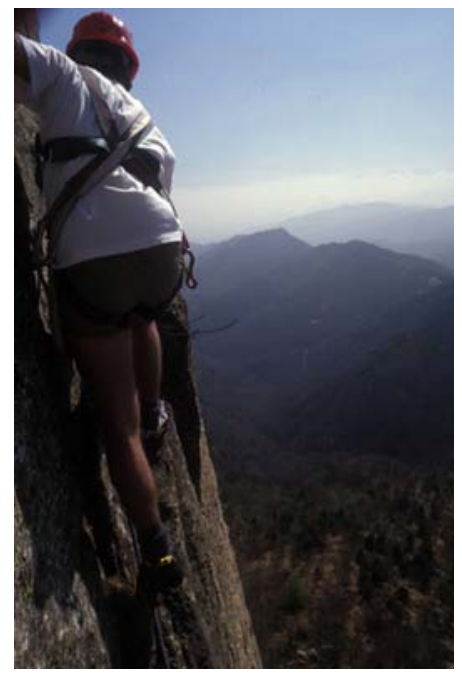

Figure 52: Rocca Sbarua.

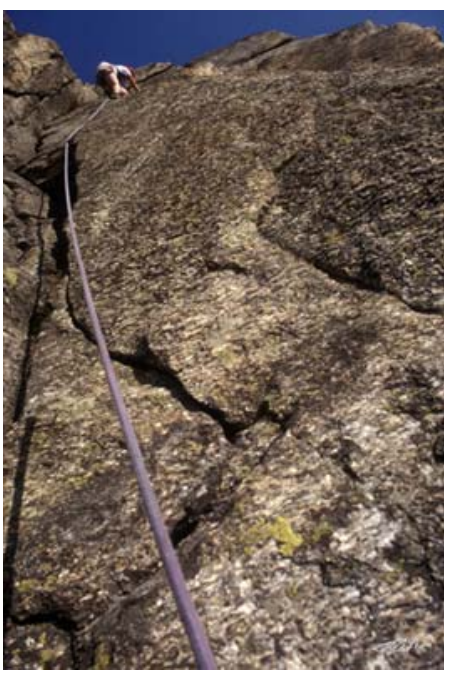

Figure 53: Rocca Sbarua.

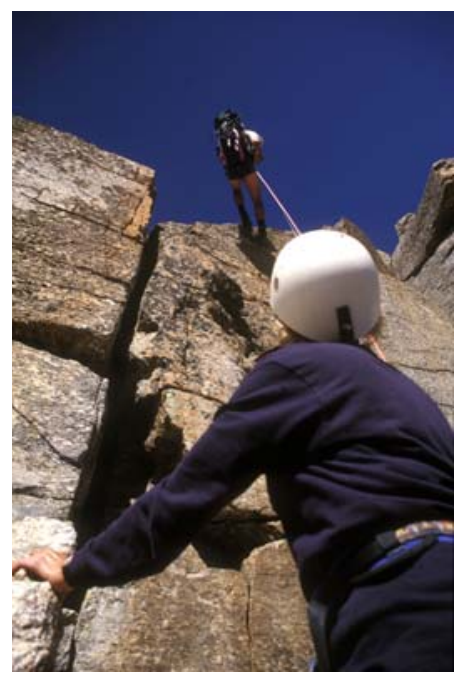

Figure 54: Tribolazione Peak. 


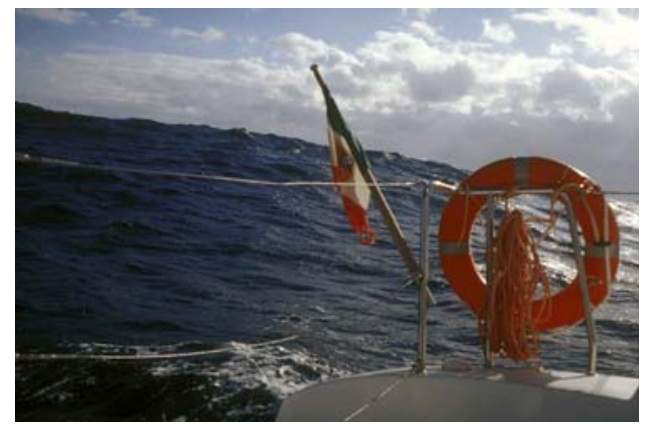

Figure 55: An Atlantic wave.

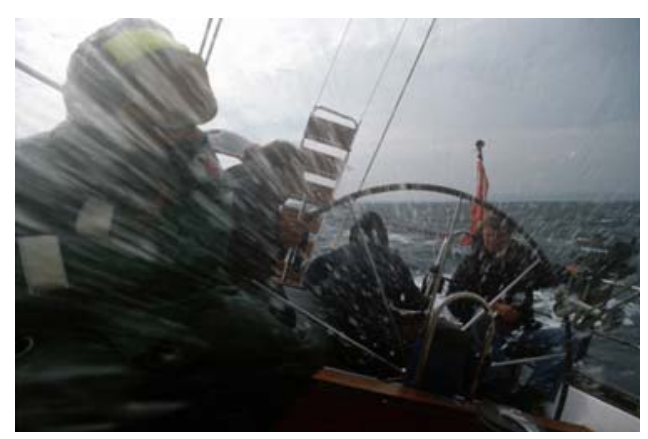

Figure 57: On the Cote d' Azur (France).

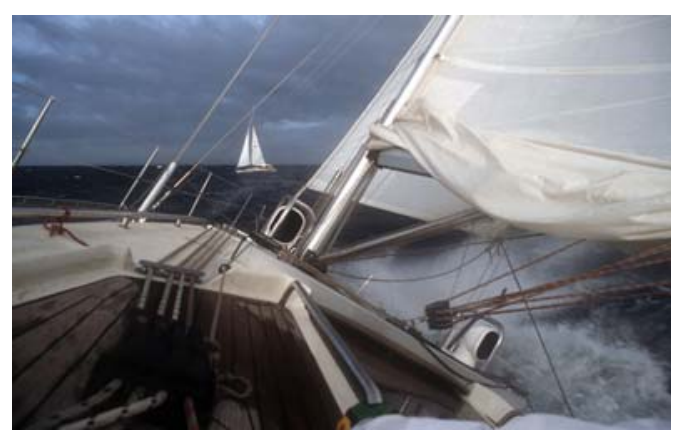

Figure 59: The 'Bocche di Bonifacio' in winter.

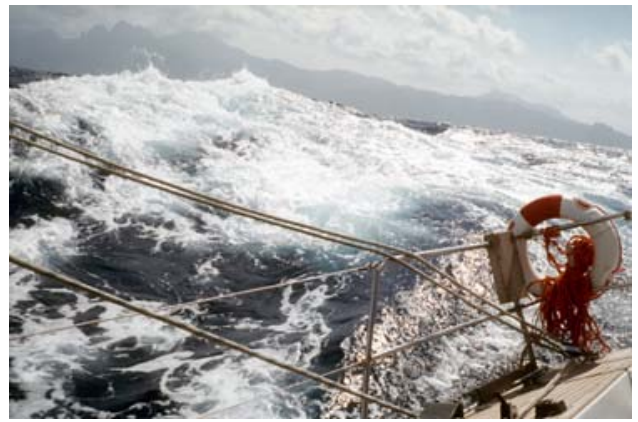

Figure 56: Tempestuous sea, Corsica.

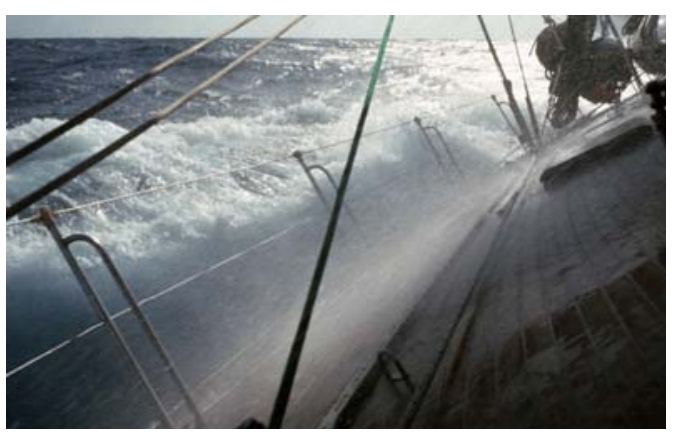

Figure 58: Crossing from Corfu to Malta.

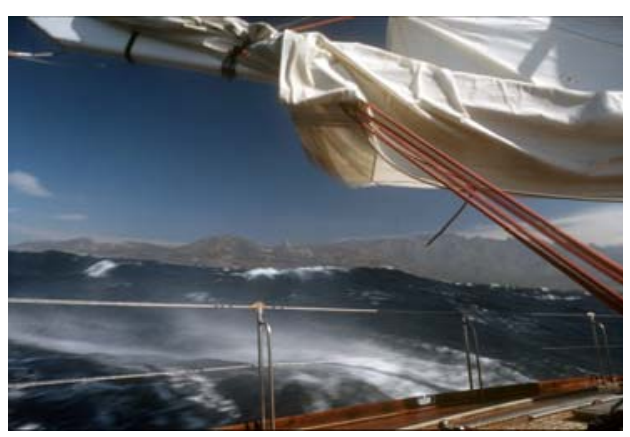

Figure 60: A strong wind, Corsica. 


\section{CONCLUSIONS}

It is becoming constantly clearer what an extremely powerful instrument the camera is and how effective it is in making us aware of our surroundings and revealing their inner nature.

In the continual shaping of the series of unique aspects of the world around us, through photography we can discover details and light effects which would otherwise escape our notice, both in their specific content, especially through use of different lenses and in the way we perceive them subjectively, as we would probably never do otherwise.

Both the photographer, who devotes his efforts creatively to this process, and those who observe the images and interpret them according to their personalities are enriched by photography in this capacity for feeling and knowledge of themselves.

\section{NOTE}

All the photographs included in the paper were taken by Pier Paolo Strona, who holds their copyright.

\section{REFERENCES}

[1] Grazioli, G., L'interpretazione musicale, Einaudi, 1952.

[2] Getreau, F., (ed), Chopin and the Pleyel sound, Edizioni Villa Medici Giulini S.r.l., 2010.

[3] Strona, P.P., Capturing the light, 1st International Conference on Light in Engineering, Architecture and the Environment, Poznan, 2011. doi: http://dx.doi.org/10.2495/LIGHT110201

[4] Strona, P.P., Torino Surreale, Editrice Morra, Almese (To), 2002.

[5] Jannon, G., (ed.), In viaggio con la cometa, Editrice Morra, Almese (To), 1997. 